\title{
EL “EVANGELIO ETERNO” EN EL MENSAJE DEL PRIMER ÁNGEL EN APOCALIPSIS 14:61
}

\author{
Oscar Mendoza Orbegoso \\ FACULTAD DE TEOLOGIA - UPEU
}

\section{Introducción}

Se han dado distintas interpretaciones sobre la expresión "evangelio eterno" proclamado por el primer ángel de Apocalipsis 14:6, 7. Unos entienden que la esencia de este es la adoración a Dios; ${ }^{2}$ otros suponen que es "sola gracia y sola cruz" para la salvación del ser humano. ${ }^{3}$ En algunos casos, en el mensaje del primer ángel más se ha enfatizado el "juicio" que el "evangelio eterno". 4

Frente a esta discusión, el presente artículo tiene dos objetivos: (1) estudiar el significado y el objetivo del "evangelio eterno" y (2) comprender qué implica aceptarlo pero en el contexto del Mensaje de los tres ángeles (en adelante Mta).

Este artículo será abordado desde la perspectiva contextual -bíblica; básicamente analizando el contexto literario de Apocalipsis 14:6 y el término evangelio tanto en el AT y NT. Para finalizar, se estudiará los frutos del "evangelio eterno" a la luz del Mta.

${ }^{1}$ Esta pesquisa fue expuesta en el V Simposio Bíblico-Teológico "Pecado y Salvación en las Escrituras”, organizado por la Sociedad de Investigación Teológica (SUHIT) de la Universidad Peruana Unión, Lima - Perú, 12 de Mayo, 2009.

${ }^{2}$ Entre ellos R. A. Taylor, Apocalipsis: un comentario de referencia, trad. Alejandro Field, Apocalipsis, http://www.salvacioneterna.com/s_rev.pdf (consultado: 14 de Julio, 2010).

${ }^{3} \mathrm{Si}$ bien es cierto la salvación del ser humano es por la misericordia de Dios, en este artículo el autor se refiere a "sola gracia y sola cruz" al pensamiento no bíblico "una vez salvo por la cruz, salvo para siempre", el cual es muy divulgado en el círculo evangélico. Este pensamiento deja de lado los frutos de la fe y la labor Sumo Sacerdotal de Cristo en el santuario celestial.

${ }^{4}$ Tanto el movimiento millerita como los pioneros del adventismo entendieron el mensaje del primer ángel como "la hora de su juicio ha llegado". Ver Alberto Timm, El santuario y el mensaje de los tres ángeles: factores integradores en el desarrollo de las doctrinas de la Iglesia Adventista del Séptimo Día, trad. Joel B. Leiva (Lima: Editorial Imprenta Unión, 2004), 49-51. 


\section{Contexto: Apocalipsis 12 al 14}

El libro de Apocalipsis está dividido básicamente en tres partes: ${ }^{5}$ (1) histórica (1-11), (2) intermedia (12-14; la historia y la escatología están entretejidas) y (3) escatológica (15-22). Apocalipsis 14:6 está ubicado en la parte intermedia, principalmente en el contexto simbólico ${ }^{6}$ y escatológico de Apocalipsis 14. Este capítulo está estructurado de la siguiente manera:
A. vV. 1-5
Los 144000 con el Cordero en el Monte Sion
B. vv. 6-12
El mensaje de los tres ángeles
C. v. 13
Paréntesis: una bienaventuranza
D. vv. $14-20$
La cosecha y la segunda venida

El capítulo 14 no está en orden progresivo. Los primeros cinco versículos (A) tratan sobre los 144000 con el Cordero (Jesucristo) en el cielo; hecho que sucederá después de la 2 da venida. En B se proclama el $M t a,{ }^{7}$ el cual, por su contenido, es proclamado antes de la caída de las siete plagas y representa el último llamado de Dios a los moradores de la tierra. Luego, en $\mathrm{C}$ se declara una bienaventuranza. Por último, en D se produce la gran cosecha de los redimidos y la 2 da venida de Cristo.

En base a esta breve explicación, se concluye que el objetivo principal del capítulo 14 es mostrar la misión del remanente en la crisis venidera y el producto de ella. Dicho producto se ve al relacionar los 144000 , el mensaje tri-angélico, la cosecha y la 2 da venida. Por lo registrado, los 144000 serán el fruto de la proclamación del Mta, puesto que este grupo

${ }^{5}$ En esta investigación, por "historia" se refiere a los eventos ocurridos a lo largo de la era cristiana hasta el año 1798 D. C., fecha que inició "tiempo del fin"; y por "escatología", a los sucesos finales iniciados en este año hasta la eternidad.

${ }^{6}$ Varios símbolos están registrados en el capítulo 14, tales como: "los 144000 con el Cordero" (v. 1), "contaminarse con mujeres" (v. 4), "castos" (v. 4), "la bestia y su marca" (v. 9), "la gran ramera: Babilonia" (v. 8). Éstos determinan que "ángel” no puede ser literal sino simbólico. Como tal, éste representa a un movimiento cumpliendo la misión en el tiempo del fin. Dicho movimiento es el remanente de Apocalipsis 12:17.

${ }^{7}$ Para una exposición acerca del Mensaje de los tres ángeles, ver Oscar Mendoza Orbegoso, "El mensaje del remanente en el tiempo del fin: el mensaje de los tres ángeles en Apocalipsis 14:6 - 12 - Parte I", Estrategias 6, no. 2 (2009): 77-86 y "El mensaje del remanente en el tiempo del fin - Parte II" en este número. 
selecto ha aceptado y ha proclamado este mensaje.

\section{El "evangelio eterno"}

El "evangelio eterno" está en el contexto del Mta, principalmente en el mensaje del primer ángel. En él se tratan cuatro aspectos, y son los siguientes: (1) "evangelio eterno", (2) "temed a Dios y dadle gloria”, (3) "juicio" y (4) "adorar al Creador". Sin embargo, en esta sección sólo se estudiará el significado del primero. Para ello, se analizará el término evangelio a lo largo de las Escrituras.

La palabra "evangelio" viene del término griego "evangelion" y básicamente significa "buenas nuevas", "victoria"9 y "noticia". En la literatura griega del siglo I d.C., éste se refería tanto a la muerte del enemigo como el arribo del emperador romano que liberaba y salvaba de la tribulación, lo cual expresaba victoria. ${ }^{10}$ En el contexto mesiánico, éstas eran "buenas nuevas de salvación por parte del Mesías".

En el AT, "evangelio" corresponde al término hebreo berah (06 veces) que significa "traer noticia", 11 "mensaje de recompensa", "recompensa por la buena nueva" (2 S 4:10; o tan sólo "recompensa" como en 18:22), "buena noticia" (2 S 18:20, 22) y "buenas nuevas" (2 S 18:20, 25, 27; 2 R 7:9). Normalmente $b^{e}$ sorah está en un contexto de notificar algo.

En el NT, evangelion aparece 76 veces y siempre se refiere al mensaje de salvación por parte de Dios. ${ }^{12}$ Mayormente sus usos están

${ }^{8}$ Este "juicio" es el juicio pre advenimiento iniciado en el año 1844 d.C. e incluye el juicio que se emitirá en la segunda venida de Cristo. Para un estudio sobre la naturaleza del juicio en las Escrituras, véase Gerhard F. Hasel, "Divine Judgment", en Handbook of Seventh-day Adventist Theology, ed. Raoul Dederen (Hagerstown: Review and Herald, 2000), 815-56; Jirí Moskala, "Toward a Biblical Theology of God's Judgment: A Celebration of the Cross in Seven Phases of Divine Universal Judgment (An Overview of a Theocentric-Christocentric Approach)", Journal of the Adventist Theological Society 15, no. 1 (2004): 138-68. En adelante JATS.

${ }^{9} \mathrm{U}$. Becker, "evangelion", en The New Internacional Dictionary of New Testament Theology, ed. Colin Brown (Grand Rapids, MI: Zondervan Publishing, 1986), 2:107.

${ }^{10}$ Gerhard Kittel, "evangelion”, en Theological Dictionary on the New Testament (Grand Rapids, MI: Eerdmans Publishing Company, 1978), 2:722.

${ }^{11}$ Especialmente en relación a encuentros militares. R. Laird Harris, ed., "evangelion", en Theological Wordbook of the Old Testament (Chicago: Moody Press, 1981), 120.

${ }^{12}$ Barbara Friberg, Timothy Friberg y Neva F. Miller, "evangelion”, en Analytical Lexicon 
dentro de frases compuestas como: (1) "la verdad del evangelio", (2) "mi/nuestro evangelio", (3) "el evangelio del reino", (4) "el evangelio de Dios”, (5) “evangelio del Señor”, (6) "evangelio de Cristo” y (7) "predicar el evangelio". 13

En Mateo, Marcos y Lucas aparece 12 veces. Para Mateo (4:23; $9: 35 ; 24: 24 ; 26: 13)$, el evangelion es un mensaje de buenas nuevas del reino de los cielos, las cuales han de ser predicadas a todo el mundo. En otras palabras, ésta es una necesidad mundial (al igual que para Marcos $[13: 10 ; 14: 9 ; 16: 15])$.

Según Marcos, evangelion está ligado al Hijo de Dios como mensajero y como centro de las "buenas nuevas de Dios" $(1: 1,14)$. Para aceptar este mensaje se necesita fe y arrepentimiento de los pecados (1:15). Por otra parte, al dejar todo y morir por el "evangelio", se salvará o se perderá la vida eterna $(8: 35 ; 10: 29)$.

Para Lucas, evangelion es un mensaje que tiene como centro la gracia de Dios (Lc 20:24; Hch 15:7).

De acuerdo con Pablo, el evangelion es un misterio (Ef 6:19) que fue revelado a los profetas del AT y que continúa en el NT (Ro 1:2; 15:25, 26). Este mensaje trata sobre el Hijo de Dios (Ro 1:3, 9; 15:19; 2 Co $2: 12 ; 2$ Co 10:14) y la gracia divina que el hombre pecador recibe por medio de Él (Ro 1:5; Gá 1:6; Fil 1:7). ${ }^{14}$ A la vez, este es un don que muestra el poder de Dios para la salvación tanto del judío como del gentil (Ro 1:16; Gá 1:11; 1 Ti 1:5, 11; Gá 2:7; Ef 3:6; 1:13). Dicha salvación fue gracias a la muerte y resurrección de Cristo en la cruz (2 Ti 2:8). ${ }^{15}$ Después de este sacrificio, el ser humano puede presentarse arrepentido y con fe a la presencia de Dios para obtener oportuno socorro, puesto

of the Greek New Testament (Grand Rapids, MI: Baker Books, 2000), 210.

${ }^{13}$ Johm R. Kohlenberger III, et al., "evangelion", en The Greek English Concordance to the New Testament with the New International Version (Grand Rapids, MI: Zondervan, 1997), 320.

${ }^{14} E n$ sí, más que un acto, evangelion es una persona: Jesucristo (2 Co 11:4).

${ }^{15}$ En la cruz se vio tanto la justicia como la misericordia de Dios. Por un lado la justicia, puesto que el ser humano tenía que morir. La raza humana pecó y tenía que recibir la consecuencia del pecado, a saber, la muerte eterna (Ro 6:23). Sin embargo, Jesucristo entregó su vida por nosotros, convirtiéndose así en nuestro sustituto. Por este sacrificio la paga del pecado humano fue saldada y la justicia de Dios fue revelada. Por otro lado la misericordia, porque fue Dios mismo el que envió a su Hijo a morir por nosotros. Él nunca desamparó al ser humano. Por su misericordia el hombre tuvo un sustituto. De esta manera, en la cruz Dios fue justo y misericordioso a la vez. 
que "este acto [en la cruz] conmemora nuestra redención del pecado y nuestra reconciliación con el cielo (Ro 3:21-25)". ${ }^{16} \mathrm{Al}$ presentarse de esta manera, y aquí viene el objetivo principal del evangelion, el pecador es justificado por Dios (Ro 1:16, 17).

Aceptar el evangelion implica vivir conforme a éste; puesto que, según Pablo y Pedro, evangelion también es un nuevo estilo de vida (1 Co 9:12, 14, 18, 23; Gá 2:14; Fil 1:27) y una confesión de fe reflejada a través de la obediencia ( 2 Co 9:13; 1 P 4:17). Asimismo, él está relacionado con la esperanza de la 2 da venida $(\mathrm{Col} 1: 5,23)$. Por lo escrito, aquellos que no lo obedecen serán condenados (2 Ti 1:8), pero los que lo aceptan recibirán la gloria de Cristo (2 Ti 2:14).

En conclusión, el evangelio, según las Escrituras, es un mensaje de salvación divina, la cual se obtuvo gracias a la muerte de Cristo en la cruz y hoy es ofrecida gratuitamente al ser humano pecador.${ }^{17} \mathrm{El}$ propósito del evangelio es salvar al ser humano.

Por otra parte, el evangelio del primer ángel es eterno. El mismo evangelio presentado en el AT y NT en los textos de Génesis 3:15, Daniel 9:24-27, Habacuc 2:4, Juan 3:16, etc. Al ser eterno, el evangelio en el tiempo del fin no será otro; será el mismo presentado en las Escrituras: Dios ofreciendo gratuitamente la salvación al ser humano.

Un punto importante que se tiene que considerar al estudiar el evangelio es el papel que cumple el santuario celestial (Heb 9:12). Si bien es cierto el término griego evangelion no aparece en la carta a los Hebreos, éste es desarrollado por Pablo pero a la luz de la labor Sumo sacerdotal de Jesucristo en su santuario. Léase Hebreos 4:1416 y 9:12:

Teniendo, pues, un gran sumo sacerdote que trascendió los cielos, Jesús $[\ldots]$ Porque no tenemos un sumo sacerdote que no pueda

${ }^{16}$ Mendoza, "El mensaje del remanente - Parte I", 80.

${ }^{17}$ Herbert Douglas, para saber en qué consiste el evangelio eterno, formula tres preguntas claves relacionadas al ministerio terrenal de Cristo. Éstas son: ¿Por qué murió Jesús?; ¿Por qué vino Jesús?; ¿Cuál es el objetivo del evangelio? Las respuestas son: murió para redimirnos, vino para salvarnos y el objetivo es restaurarnos. Herbert Douglas, "What Is the 'Everlasting Gospel?", JATS 12, no. 2 (2001): 145-51. 
compadecerse de nuestras flaquezas [...] Por tanto, acerquémonos con confianza al trono de la gracia para que recibamos misericordia, y hallemos gracia para la ayuda oportuna.

[...] y no por medio de la sangre de machos cabríos y de becerros, sino por medio de su propia sangre, entró al Lugar Santísimo ${ }^{18}$ una vez para siempre, habiendo obtenido redención eterna.

Como declaran estos textos, los actos salvíficos de Dios a favor del ser humano no concluyeron en la cruz. Más bien, éstos también son realizados en el santuario celestial. El ser humano no sólo es salvo únicamente por la cruz sino también por la intercesión del Sumo Sacerdote Jesucristo. Por este motivo, no se puede comprender plenamente el evangelio eterno si no se lo estudia a la luz del santuario celestial. Por estas razones, es imposible entender el evangelion en un solo acto, sino en un conjunto de acciones salvíficas de Dios dentro de un plan establecido por Él; esto incluye la muerte de Cristo en la cruz y su intercesión en el santuario.

Después de este análisis, se concluye que el "evangelio eterno" es la salvación por la fe. Éste no es ni adoración ni tiene como único énfasis el juicio, mucho menos "sola gracia y sola cruz" sin los frutos respectivos. El evangelion es Dios salvando al hombre del pecado y no en el pecado.

\section{El "evangelio eterno" y sus frutos}

Para encontrar los frutos del "evangelio eterno", se estudiará Apocalipsis 14:6-12, puesto que en estos siete versículos hay elementos que forman parte de la respuesta del justificado a Dios; y son los siguientes:

(1) "Temed y dadle gloria". Implica reverenciar a Dios y mostrar los frutos de la fe. En el NT, el cristiano glorifica a Dios a través de sus buenas obras (Jn 15:8; Ro 8:18-21).

(2) “Adorad al Creador". En Apocalipsis tiene una connotación de homenaje u obediencia. ${ }^{19}$ En el contexto de Apocalipsis 12 al 14,

${ }^{18}$ Una mejor traducción del griego al español no es "Lugar Santísimo" sino "santuario".

${ }^{19}$ Raymond Holmes, "La adoración en el libro de Apocalipsis", Theologika 15, no. 1 
adorar implica guardar los mandamientos de Dios, incluyendo reposar el séptimo día.

(3) "No contaminarse con Babilonia". ${ }^{20}$ No creer ni practicar, voluntaria e involuntariamente, las falsas enseñanzas de este poder opresor.

(4) "Guardar los mandamientos". ${ }^{21}$ Obedecer la ley de Dios de Éxodo 20:3-17.

(5) “Tener la fe de Jesús". Aceptar las enseñanzas de Jesucristo. Esto incluye las verdades reveladas a los profetas que se encuentran en la Palabra de Dios (cf. 12:17; 19:10; 22:8-9).

El primer ángel proclama el "evangelio eterno", asimismo, invita a "adorar al Creador" y a "temed y dadle gloria". Por lo registrado, el remanente no sólo llama al mundo a creer y a aceptar el evangelio, sino también lo que éste produce: un nuevo estilo de vida en Cristo. Una vida de adoración y reverencia al Creador.

El segundo ángel declara que Babilonia ha caído y advierte que todo verdadero adorador no tiene que seguir contaminándose con sus falsas enseñanzas. En este sentido, aquel que ha aceptado el "evangelio eterno" rechazará las falsas enseñanzas de Babilonia y se someterá únicamente a la autoridad de la Biblia y lo que ella enseña.

El tercer ángel registra cómo vive aquella persona que ha aceptado el "evangelio eterno", a saber, guardando los mandamientos de Dios y la fe de Jesucristo (v. 12). ${ }^{22}$ Esta obediencia y fidelidad determinarán

(2000): 14. Holmes, al relacionar el evangelio eterno y la adoración, declara: "El resultado de la proclamación del 'evangelio eterno' aumenta el número de aquellos que adoran a Dios, pero el blanco final del evangelismo es producir verdaderos adoradores”. Ibid., 20.

${ }^{20} \mathrm{Si}$ bien es cierto "no contaminarse con Babilonia" no está registrado en Apocalipsis 14:8, éste es ampliado en 18:4. El mensaje de 18:4 no es un "cuarto mensaje angélico" sino la ampliación del mensaje del segundo ángel del cap. 14.

${ }^{21}$ Para un estudio sobre los "mandamientos de Dios" en Apocalipsis 12:17 y 14:12 y su papel escatológico, ver William Shea, "The Controversy over the Commandments in the Central Chiasm of Revelation", JATS 11, no. 1-2 (2000): 216-31; Oscar Mendoza Orbegoso, "Alusiones al sábado en Apocalipsis 12 al 14", Berit Olam 7, no. 1 (2010): 156-62.

${ }^{22}$ Hans LaRondelle declara: "En vista de la amenaza final del anticristo, Dios requiere una fidelidad doble: fidelidad al testimonio de Jesús y obediencia a los mandamientos de Dios (Ap 
quién recibirá el sello de Dios y quién será marcado por la bestia.

En conclusión, no se puede separar el evangelio y los frutos que éste produce. Evangelio sin frutos, a la luz de las Escrituras, no es evangelio.

\section{Conclusión}

(1) El "evangelio eterno" no es "adorad al Creador" ni "la hora de su juicio ha llegado"; a lo largo de la Biblia, nunca se lo define como “juicio" o como "adoración”. El "evangelio eterno" predicado por el primer ángel es la "Justificación por la fe".

(2) El pecador arrepentido necesita fe para que Dios obre en su propia vida y así efectúe dicho acto salvífico. Esta obra de salvación es gracias a Dios por medio de Jesucristo. Él, a través de su ministerio terrenal (por medio de su muerte y resurrección) y celestial (a través de su sumo sacerdocio), salva al ser humano pecador, quien por fe acude al santuario celestial para recibir oportuno socorro (Heb 4:16).

(3) Después de haber aceptado por fe el "evangelio eterno", el justificado mostrará los frutos de aquella fe "guardando los mandamientos de Dios (incluyendo el sábado), teniendo fe en el "Testimonio de Jesucristo" (14:12; cf. 12:17; 19:10; 22: 8, 8), adorando al Creador y dándole gloria a través de sus buenas obras.

(4) Apocalipsis 14:6 y 12 no habla de sola gracia, sola fe y sola cruz. Justificación y sus respectivos frutos, a la luz del santuario, integran la verdad del evangelio.

(5) Si bien es cierto existen muchas verdades en la Palabra de Dios que son aprendidas y predicadas, el mensaje principal del remanente, a la luz del Mta y de la Biblia, es el "evangelio eterno".

14:12)". Hans LaRondelle "El remanente y el mensaje de los tres ángeles”, en Teología: fundamentos bíblicos de nuestra fe, ed. Raoul Dederen, trad. David Gullón (Doral, FL: Asociación Publicadora Interamericana, 2008), 8:206. 